p-ISSN 1693-9484, $e$-ISSN : 2621-8313

Majalah Ilmiah Bahari Jogja (MIBJ)

Vol. 17 No. 2, Juli $2019 \quad$ (73-83)

DOI : 10.33489/mibj.v17i2.203

(C) 2019 Akademi Maritim Yogyakarta

BAHARI JOG]A

\title{
Pengaruh Lingkungan Kerja Fisik dan Non Fisik Terhadap Kebosanan Kerja Karyawan di Akademi Maritim Yogyakarta (AMY)
}

\author{
Himawan Aditya Pratama ${ }^{*}$ \\ ${ }^{1}$ Akademi Maritim Yogyakarta, Jl. Magelang KM 4.4, Yogyakarta 55284, Indonesia \\ * Corresponding Author. E-mail : himawan.aditya.pratama@gmail.com.
}

Telp : 081227522776

\begin{abstract}
Abstrak
Penelitian ini bertujuan untuk mendeskripsikan dan menjelaskan pengaruh lingkungan kerja baik fisik ataupun non fisik dari salah satu institusi pendidikan swasta di Yogyakarta yang berlokasi di Akademi Maritim Yogyakarta (AMY) Jenis penelitian yang digunakan dalam penelitian ini adalah penelitian penjelasan (explanatory research) dengan pendekatan kuantitatif. Populasi dalam penelitian ini adalah semua karyawan tetap AMY yang berjumlah 40 orang. Teknik analisis data yang digunakan adalah analisis statistik deskriptif dan analisis statistik inferensial, analisis statistik inferensial yang digunakan dalam penelitian ini adalah analisis regresi linier berganda. Hasil penelitian menunjukkan bahwa lingkungan kerja baik fisik maupun non-fisik berpengaruh positif dan signifikan terhadap Kebosanan kerja karyawan di Akademi Maritim Yogyakarta.
\end{abstract}

\section{Kata Kunci : Lingkungan kerja Fisik, Lingkungan Kerja non-fisik, Kebosanan kerja.}

\begin{abstract}
This study aims to describe and explain the physical or non-physical work environment of one of the educational institutions in Yogyakarta provided at the Yogyakarta Maritime Academy (AMY). The type of research used in this study is exploration research. The population in this study were all permanent employees who gathered 40 people. The data analysis technique used is descriptive statistical analysis and inferential statistical analysis, inferential statistical analysis used in this study is multiple linear regression analysis. The results showed that both physical and non-physical work environments were positively and significantly related to employee work boredom at the Yogyakarta Maritime Academy.
\end{abstract}

Keywords: Physical work environment, non-physical work environment, boredom.

\section{PENDAHULUAN}

Akademi Maritim Yogyakarta (AMY) sebagai insitusi pendidikan dan pelatihan (diklat) Kepelautan di bawah naungan Yayasan Institut Pendidikan Kemaritiman (YIPM) mengelola 3 jurusan, yaitu Jurusan Ketatalaksanaan Pelayaran Niaga, Jurusan Nautika, dan Jurusan Teknika, sangat membutuhkan pengelolaan sumber daya manusia yang berkualitas. Hal ini disebabkan manusia merupakan satu - satunya penggerak dan pengelola semua aktifitas dalam kampus 
tersebut, sehingga keberhasilan dalam mencapai tujuan perguruan tinggi tersebut tidak terlepas dari kinerja setiap pegawainya.

Kebosanan kerja merupakan salah satu fenomena umum yang kerap terjadi pada karyawan. Kebosanan sering terjadi pekerjaan yang dilakukan berulangulangatau monoton, serta pekerjaan yang cenderung tidak menarik. Namun menurut Anies (2005) ada kalanya kebosanan dapat disebabkan oleh hal-hal yang semula dianggap menyenangkan namun kelamalamaan berubah menjadi membosankan.

Dalam melakukan pekerjaan, seorang pekerja pasti ada kalanya merasa jenuh ataupun bosan. Salah satu akibat dari pekerjaan yang perlu mendapat perhatian adalah timbulnya rasa kebosanan kerja dan kelelahan kerja khususnya mereka yang bekerja pada pekerjaan - pekerjaan, berulang - ulang, kurang bervariasi, dan kurang tantangan (Sedarmayanti, 2007).

Dalam menangani kebosanan kerja ada beberapa hal yang perlu dilakukan, yaitu menganalisis faktor yang menyebabkan karyawan merasa bosan terhadap pekerjaannnya. Faktor - faktor tersebut dapat terlihat dalam sejumlah kebisaan yang dapat dikenali dengan baik beberapa diantaranya adalah bolos kerja, keterlambatan, perubahan kerja yang banyak, perdebatan dan bahkan kekerasan fisik.

Penelitian ini mengacu kepada beberapa penelitian sebelumnya tentang pengaruh lingkungan baik secara fisik atau nonfisik terhadap kebosanan kerja karyawan. Berdasarkan penelitian sebelumnya tersebut penulis ingin mengetahui pengaruh nyata lingkungan kerja baik fisik dan nonfisik di Akademi Maritim Yogyakarta (AMY).

Tabel 1. Lingkungan kerja berpengaruh terhadap kebosanan

\begin{tabular}{|c|c|c|}
\hline \multicolumn{3}{|c|}{ Lingkungan kerja berpengaruh terhadap Kebosanan } \\
\hline $\begin{array}{l}\text { Pengaruh Lingkungan Kerja } \\
\text { fisik dan non fisik terhadap } \\
\text { tingkat Stres dan Kejenuhan } \\
\text { Karyawan } \\
\text { Oleh : } \\
\text { Yosep Budi Prasetya } \\
2009\end{array}$ & $\begin{array}{l}\text { Lingkungan kerja fisik } \\
\text { Lingkungan kerja non fisik } \\
\text { Kejenuhan }\end{array}$ & $\begin{array}{l}\text { Lingkungan kerja Kerja Fisik } \\
\text { dan Lingkungan kerja non } \\
\text { fisik secara simultan } \\
\text { berpengaruh terhadap } \\
\text { kejenuhan kerja karyawan } \\
\text { sebesar } 4,3 \% \text {. }\end{array}$ \\
\hline $\begin{array}{l}\text { Effect of Work Environment } \\
\text { on level of work stress and } \\
\text { burnout among nurses in a } \\
\text { teaching hospital in Nigeria } \\
\text { Oleh : } \\
\text { Guobadia Pauline Ojekou } \\
\text { Odetola Titilayo Dorothy } \\
2015\end{array}$ & $\begin{array}{l}\text { Lingkungan kerja } \\
\text { Stres kerja } \\
\text { Kejenuhan }\end{array}$ & $\begin{array}{l}\text { Limgkungan kerja } \\
\text { berpengaruh signifikan } \\
\text { terhadap burnout }\end{array}$ \\
\hline $\begin{array}{l}\text { Working Environment and } \\
\text { Burnout Syndrome } \\
\text { Oleh : } \\
\text { Elide Sbardelloto M da Costa } \\
\text { Adriano Hyeda } \\
\text { Eliane M C P Maluf }\end{array}$ & $\begin{array}{l}\text { Lingkungan kerja } \\
\text { Kejenuhan }\end{array}$ & $\begin{array}{l}\text { lingkungan memiliki } \\
\text { hubungan yang signifikan } \\
\text { dengan risiko burnout, } \\
\text { terutama peran pemimpin } \\
\text { dalam manajemen karyawan }\end{array}$ \\
\hline
\end{tabular}




\begin{tabular}{|l|l|l|}
\hline 2016 & & \\
\hline $\begin{array}{l}\text { Nurse burnout and the } \\
\text { working environment }\end{array}$ & $\begin{array}{l}\text { Kejenuhan } \\
\text { Lingkungan kerja }\end{array}$ & $\begin{array}{l}\text { lingkungan kerja mempunyai } \\
\text { pengaruh dalam mengurangi } \\
\text { risiko perawat mengalami } \\
\text { burnout. }\end{array}$ \\
$\begin{array}{l}\text { O'Mahony N } \\
2011\end{array}$ & $\begin{array}{l}\text { The impact of the work } \\
\text { environment on Job Burnout }\end{array}$ \\
$\begin{array}{l}\text { Oleh : } \\
\text { Konstantina Rentzou } \\
2014\end{array}$ & $\begin{array}{l}\text { Lingkungan kerja } \\
\text { Kejenuhan kerja }\end{array}$ & $\begin{array}{l}\text { kelelahan emosional terjadi } \\
\text { pada guru berhubungan } \\
\text { dengan kondisi tempat kerja } \\
\text { yang negatif, tidaklah } \\
\text { mengherankan bahwa burnout } \\
\text { dapat terjadi. }\end{array}$ \\
\hline
\end{tabular}

Sumber : Data sekunder diolah, 2018

Tabel 2. Lingkungan pekerjaan tidak berpengaruh terhadap kebosanan

\begin{tabular}{|c|c|c|}
\hline \multicolumn{3}{|c|}{ Lingkungan pekerjaan tidak berpengaruh terhadap kebosanan } \\
\hline $\begin{array}{l}\text { Pengaruh Beban Kerja, } \\
\text { Lingkungan Kerja, dan } \\
\text { dukungan sosial terhadap } \\
\text { Burnout pustakawan di kota } \\
\text { Mataram. } \\
\text { Oleh : } \\
\text { Lalu Ciptadi Romadhoni, } \\
\text { Thatok Asmony dan Mukmin } \\
\text { Suryatni } \\
2015\end{array}$ & $\begin{array}{l}\text { Lingkungan kerja } \\
\text { Burnout }\end{array}$ & $\begin{array}{l}\text { variabel lingkungan } \\
\text { kerja secara parsial tidak } \\
\text { berpengaruh terhadap burnout } \\
\text { pustakawan di Kota Mataram. } \\
\text {. }\end{array}$ \\
\hline $\begin{array}{l}\text { Burnout pada karyawan } \\
\text { ditinjau dari persepsi terhadap } \\
\text { lingkungan kerja psikologis } \\
\text { dan jenis kelamin } \\
\text { Oleh : } \\
\text { Imelda Novelina Sihotang } \\
2004\end{array}$ & $\begin{array}{l}\text { Lingkungan kerja } \\
\text { Burnout }\end{array}$ & $\begin{array}{l}\text { Analisis data menunjukkan } \\
\text { bahwa ada lingkungan kerja } \\
\text { tidak berpengaruh terhadap } \\
\text { burnout. }\end{array}$ \\
\hline $\begin{array}{l}\text { Hubungan Antara persepsi } \\
\text { terhadap lingkungan kerja } \\
\text { psikologis dengan burnout } \\
\text { pada perawat RSU Budi } \\
\text { Rahayu Pekalongan } \\
\text { Oleh : } \\
\text { Khusnul Khotimah } \\
2010\end{array}$ & $\begin{array}{l}\text { Lingkungan kerja } \\
\text { Burnout }\end{array}$ & $\begin{array}{l}\text { Persepsi lingkungan kerja } \\
\text { tidak mempengaruhi burnout } \\
\text { pada perawat. }\end{array}$ \\
\hline
\end{tabular}

Sumber : Data sekunder diolah, 2018 


\section{Lingkungan Kerja}

\section{A. Pengertian}

Menurut Basuki (2005) lingkungan kerja adalah segala sesuatu yang berada di lingkungan yang dapat mempengaruhi baik secara langsung maupun tidak langsung seseorang atau sekelompok orang di dalam melaksanakan aktivitasnya. Menurut Robbins (2003) lingkungan adalah lembaga-lembaga atau kekuatankekuatan diluar yang berpotensi mempengaruhi kinerja organisasi, lingkungan dirumuskan menjadi dua yaitu lingkungan umum dan lingkungan khusus. Lingkungan umum adalah segala sesuatu di luar organisasi yang memilki potensi untuk mempengaruhi organisasi. Lingkungan ini berupa kondisi sosial dan teknologi. Sedangkan lingkungan khusus adalah bagian lingkungan yang secara langsung berkaitan dengan pencapaian sasaran-sasaran sebuah organisasi.

Menurut Mangkunegara (2005) lingkungan kerja yang dimaksud antara lain uraian jabatan yang jelas, target kerja yang menantang, pola komunikasi kerja yang efektif, iklim kerja dan fasilitas kerja yang relatif memadai. Nitisemito (1992) menyatakan bahwa lingkungan kerja adalah segala sesuatu yang ada disekitar para pekerja dan yang dapat mempengaruhi dirinya dalam menjalankan tugas-tugas yang dibebankan. Lingkungan kerja terdiri dari lingkungan fisik dan nonfisik yang melekat pada karyawan sehingga tidak dapa dipisahkan untuk mendapatkan kinerja karyawan yang baik. Menurut Sedarmayanti (2009) lingkungan kerja fisik adalah semua keadaan berbentuk fisik yang terdapat di sekitar tempat kerja yang dapat mempengaruhi karyawan baik secara langsung maupun secara tidak langsung. Sedangkan lingkungan kerja nonfisik adalah semua keadaan yang terjadi berkaitan dengan hubungan kerja, baik hubungan dengan atasan maupun dengan rekan kerja, ataupun hubungan dengan bawahan.

\section{B. Faktor-faktor yang Mempengaruhi Lingkungan Kerja}

Faktor-faktor lingkungan kerja menurut Nitisemito (1992), yaitu :

1) Warna.

2) Kebersihan lingkungan kerja.

3) Penerangan.

4) Pertukaran udara.

5) Jaminan keamanan.

6) dapat mengganggu konsentrasi dalam bekerja.

7) Penataan Tata ruang.

Menurut Robbins-Coulter (1999) lingkungan dapat dibagi menjadi dua :

\section{Lingkungan Umum}

Lingkungan ini berupa kondisi sosial dan ternologi suatu organisasi yang memiliki potensi untuk mempengaruhi organisasi. Antara lain:
a. Fasilitas kerja
b. Fasilitas alat kerja
c. Fasilitas perlengkapan kerja
d. Fasilitas sosial
e. Teknologi

2. Lingkungan Khusus 
Lingkungan yang secara langsung berkaitan dengan pencapaian tujuan sebuah organsasi yang dapat mempengaruhi dirinya dalam menjalankan tugastugas yang dibebankan.

\section{Indikator pengukuran Lingkungan Kerja}

Indikator-indikator lingkungan kerja oleh Nitisemito (1992) yaitu sebagai berikut:

1. Suasana kerja

Suasana kerja adalah kondisi yang ada disekitar karyawan yang sedang melakukan pekerjaan yang dapat mempengaruhi pelaksanaan pekerjaan itu sendiri. Suasana kerja ini akan meliputi tempat kerja, fasilitas dan alat bantu pekerjaan, kebersihan, pencahayaan, ketenangan termasuk juga hubungan kerja antara orangorang yang ada ditempat tersebut.

2. Hubungan dengan rekan kerja

Hubungan dengan rekan kerja sangat mempengaruhi karyawan tetap tinggal dalam satu organisasi. hubungan yang harmonis diharapakan tercipta antara rekan kerja. Karena hal tersebut merupakan faktor penunjang proses dalam bekerja.

3. Tersedianya fasilitas kerja

Kelengkapan peralatan yang digunakan untuk mendukung kelancaran kerja. Menurut Sedarmayanti (2009) indikator-indikator lingkungan kerja yaitu sebagai berikut:

a. Penerangan

b. Sirkulasi udara

c. Kebisingan di tempat kerja

d. Bau tidak sedap

e. Keamanan dan keselamatan di tempat kerja

Sedarmayanti (2009) peneliti mengambil indikator yaitu suasana kerja, hubungan dengan rekan kerja, tersedianya fasilitas kerja, penerangan, sirkulasi udara, kebisingan, bau tidak sedap, dan keamanan.

Kebosanan adalah hal yang umum terjadi bagi banyak orang di dalam kehidupan. Meski begitu, literatur-literatur mengenai definisi yang berlaku umum dari kebosanan tampaknya belum ada, namun beberapa ahli telah mengungkapkan pemahaman mereka sendiri tentang kebosanan (Tilburg, 2011).

Dari sudut pandang psikologi, kebosanan dapat dibedakan menjadi dua yaitu kebosanan karena situasi dan kebosanan sebagai sifat. Kebosanan karena situasi timbul dari kondisi di luar individu yang menstimulasi terjadinya kebosanan, sedangkan kebosanan sebagai sifat menggambarkan tentang kondisi individu yang mudah mengalami kebosanan. (Yuwanto, 2012).

Teori kebosanan kerja menurut Fahlman, Lynn, Flora dan Eastwood (2011), ada empat, yaitu : psikodinamik, gairah, perhatian dan eksistensial. Pada setiap teori terdapat penjelasan yang berbeda tentang keterlibatan setiap individu yang merasa bosan dengan dunia kerjanya. Berikut penjelasan mengenai teori - teori tersebut :

1. Psikodinamik

2. Gajah

3. Perhatian

4. Eksistensial 
Teori di atas menunjukkan bahwa ciri -ciri dari kebosanan kerja adalah pengalaman yang buruk yang terjadi pada diri karyawan dalam memenuhi keinginannya, karena ketidakmampuan diri dalam memuaskan aktivitas kerjanya (Fahlman, Lynn, Flora \& Eastwood, 2011).

Maslach \& Leiter (1997), mendefinisikan job burnout sebagai keletihan fisik dan mental secara perlahan yang diiringi dengan hilangnya komitmen kerja serta munculnya sikap sinis kepada rekan kerja mereka.

Untuk mengurangi kebosanan dalam pekerjaan dipengaruhi oleh penguasaan prosedur kerja, uraian kerja (job description), persyaratan jabatan (job specification) dan ketersediaan peralatan yang sesuai dengan lingkungan kerja, (Notoatmodjo, 2003). Menurut Papu (2002), banyak hal yang seharusnya dilakukan perusahaan untuk mengurangi kebosanan dan kejenuhan melalui kegiatan sebagai berikut: (1) adanya rotasi kerja, (2) karyawan terlibat dalam pengambilan keputusan, (3) adanya company gathering, (4) memberikan kesempatan untuk melakukan cuti.

\section{Faktor - faktor yang mempengaruhi}

Kebosanan sesuatu yang dipandang penting bagi manajer Sumber Daya Manusia (SDM), menurut (Cheyne dkk,2006), membagi dalam tiga katagori kebosanan yang meliputi: (1) melarang individu terlibat dalam beberapa aktivitas yang diinginkan, (2) memaksa untuk mengikuti beberapa aktivitas yang tidak diinginkan, (3) individu melaksanakan kegiatan tanpa memiliki perasaan senang terhadap kegiatannya.

Hurrell, dkk (1988) dalam Hendi (2014) mengemukakan bahwa ada beberapa faktor penyebab kebosanan dalam bekerja, yaitu meliputi:

1. Beban kerja.

2. Shift kerja.

3. Jam kerja.

4. Rutinitas.

5. Kompleksitas pekerjaan.

6. Tuntutan pekerjaan tidak sesuai dengan keterampilan.

\section{E. Ciri - ciri Orang mengalami Kebosanan}

Terdapat beberapa ciri orang yang merasa tidak ada kesesuaian dengan pekerjaannya atau terjadi kebosanan kerja, menurut berbagai hasil temuan dapat dikemukakan sebagai berikut :

1. Orang yang bosan akan terlihat mudah marah, cenderung tidak sabaran, kurangnya perhatian dan usaha pada apa yang dikerjakan (Tilburg, 2013).

2. Orang yang bosan cenderung menunda pekerjaan, sering melakukan kesalahan, tidak menyelesaikan pekerjaan secara penuh, dan motivasi rendah (Vodanovich, 2003).

3. Orang yang bosan cenderung sering meninggalkan pekerjaan lebih awal dari waktu yang seharusnya (Craparo, Faraci, Fasciano, Carruba dan Gori, 2013)

4. Orang yang bosan cenderung memiliki performa kerja serta absensi karyawan yang rendah (Fahlman, 2009).

\section{F. Pengukuran Kebosanan Kerja}

Job Burnout memiliki indikator yang tidak biasa yang dapat menimbulkan hilangnya gairah dalam bekerja. Job Burnout terjadi karena proses kumulatif, yang 
ketika gejala awal sudah diabaikan maka dapat berkembang menjadi kondisi yang serius. Potter (2005) menjelaskan indikator job burnout yaitu :

1) Emosi Negatif.

2) Frustasi

3) Depresi

4) Masalah Kesehatan

5) Kinerja Menurun

\section{METODE}

\section{Lokasi Penelitian}

Penelitian ini memilih lokasi pada Akademi Maritim Yogyakarta yang terletak di Jl. Magelang km 4,4 Yogyakarta 55165, Yogyakarta.

\section{Populasi dan Sampel}

Dalam penelitian ini yang menjadi populasi penelitian adalah seluruh karyawan tetap pada Akademi Maritim Yogyakarta sejumlah 40 orang.

Data yang dipergunakan dalam penelitian ini adalah data primer yaitu data yang diperoleh langsung dari sumber data dan berhubungan langsung dengan permasalahan yang akan dikaji. Dalam penelitian ini menggunakan data subyek tertulis yaitu berupa hasil kuesioner.

\section{Metode Pengumpulan Data}

Dalam penelitian ini digunakan Kuisoner berdasarkan Skala likert (Sekaran, 2011) dengan skor 6 tingkatan, yaitu yang paling rendah diberikan skor 1 dan yang paling tinggi diberikan skor 6 .

Tabel 3. Skala likert

\begin{tabular}{|c|c|c|c|}
\hline No & Keterangan & Kode & Skor \\
\hline 1. & Sangat Setuju & SS & 6 \\
2. & Setuju & S & 5 \\
3. & Agak Setuju & AS & 4 \\
4. & Agak Tidak & ATS & 3 \\
& Setuju & & \\
5. & Tidak Setuju & TS & 2 \\
6. & Sangat Tidak & STS & 1 \\
& Setuju & & \\
\hline
\end{tabular}

\section{Teknik Analisis}

Penelitian menggunakan instrumen validitas dan reliabilitas (Sukmadinata, 2009). Pengujian Asumsi Klasik: Uji Normalitas, Uji Multikolinearitas, Uji Heteroskedastisitas. Pengujian Hipotesis, Regresi Linier Berganda, Uji t, Koefisien determinasi $\left(\mathrm{R}^{2}\right)$ dan Uji F.

Untuk menguji pengaruh variabel intervening digunakan metode analisis jalur. (Path Analysis). Analisi jalur merupakan perluasan dari analisis regresi linear berganda, atau analisi jalur adalah perluasan analisis regresi untuk menaksir 
hubungan kualitas antar variabel yang telah ditetapkan sebelumnya berdasarkan teori (Ghozali, 2013). Berikut analisis jalur yang digunakan dalam penelitian ini :

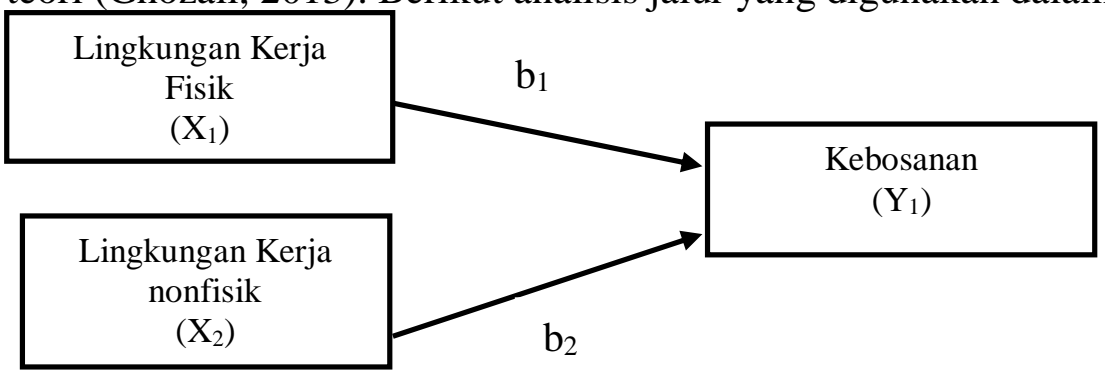

Gambar 1. Kerangka Penelitian

\section{HASIL DAN PEMBAHASAN}

Tabel 4. Interval

\begin{tabular}{|c|c|}
\hline Interval & Kategori \\
\hline $1,00 \mathrm{~s} / \mathrm{d} 1,82$ & Sangat Buruk \\
\hline $1,83 \mathrm{~s} / \mathrm{d} 2,66$ & Buruk \\
\hline $2,67 \mathrm{~s} / \mathrm{d} 3,49$ & Kurang Baik \\
\hline $3,50 \mathrm{~s} / \mathrm{d} 4,32$ & Cukup Baik \\
\hline $4,33 \mathrm{~s} / \mathrm{d} 5,16$ & Baik \\
\hline $5,17 \mathrm{~s} / \mathrm{d} 6,00$ & Sangat Baik \\
\hline
\end{tabular}

Sumber : Data primer diolah, 2018

Tabel 5. Rekapitulasi Deskriptif

\begin{tabular}{|l|c|c|}
\hline \multicolumn{1}{|c|}{ Variabel } & Rata- Rata & Keterangan \\
\hline Lingkungan Kerja Fisik $\left(\mathrm{X}_{1}\right)$ & 4,67 & Baik \\
\hline Lingkungan Kerja Non fisik $\left(\mathrm{X}_{2}\right)$ & 4,45 & Baik \\
\hline Kebosanan Kerja $\left(\mathrm{Y}_{1}\right)$ & 4,46 & Baik \\
\hline
\end{tabular}

Sumber : Data primer diolah, 2018

Dari hasil tabel 5 pengolahan data diatas diketahui bahwa nilai Rata-rata hitung masuk didalam interval 4,33 s/d 5,16. berarti variabel-variabel bias dikatakan memiliki kategori baik.

Tabel 6. Hasil Uji Multikolinearitas dengan Metode VIF

\begin{tabular}{|l|c|c|c|}
\hline \multicolumn{1}{|c|}{ Variabel } & VIF & Nilai Kritis & \multicolumn{1}{c|}{ Keterangan } \\
\hline $\begin{array}{l}\text { Lingkungan Kerja Fisik } \\
\left(\mathrm{X}_{1}\right)\end{array}$ & 1.311 & 10 & Tidak ada multikolinearitas \\
\hline $\begin{array}{l}\text { Lingkungan Kerja non } \\
\text { FIsik }\left(\mathrm{X}_{2}\right)\end{array}$ & 1.950 & 10 & Tidak ada multikolinearitas \\
\hline Kebosanan $\left(\mathrm{Y}_{1}\right)$ & 2.256 & 10 & Tidak ada multikolinearitas \\
\hline
\end{tabular}

Sumber : Data primer diolah, 2018 
Berdasarkan hasil uji multikolinearitas dengan metode VIF, nilai VIF $<10$, artinya bahwa semua variabel bebas tidak terjadi multikolinearitas, sehingga tidak membiaskan interprestasi hasil analisis regresi.

Tabel 7. Hasil Uji Heteroskedastisitas dengan Glejser

\begin{tabular}{|l|c|c|c|}
\hline \multicolumn{1}{|c|}{ Variabel } & t-statistik & Sig. & Keterangan \\
\hline $\begin{array}{l}\text { Lingkungan Kerja Fisik } \\
\left(\mathrm{X}_{1}\right)\end{array}$ & $-0,296$ & 0,768 & Homoskedastisitas \\
\hline $\begin{array}{l}\text { Lingkungan Kerja } \\
\text { nonFisik }\left(\mathrm{X}_{2}\right)\end{array}$ & $-0,537$ & 0,593 & Homoskedastisitas \\
\hline Kebosanan Kerja $\left(\mathrm{Y}_{1}\right)$ & $-0,707$ & 0,482 & Homoskedastisitas \\
\hline
\end{tabular}

Sumber : Data primer diolah, 2018

Berdasarkan hasil uji heteroskedastisitas pada tabel 7 diatas dengan menggunakan Glejser terlihat bahwa nilai signifikansinya > 0,05. Hal ini berarti model yang diestimasi bebas dari heteroskedastisitas.

Tabel 8. Hasil Regresi Linier Model Metode OLS

\begin{tabular}{|c|c|c|c|c|}
\hline Variabel & $\begin{array}{c}\text { Koefisien } \\
\text { Unstandardized }\end{array}$ & $\begin{array}{c}\text { Koefisien } \\
\text { Standardized }\end{array}$ & $\mathbf{t}$ & Sig. \\
\hline Konstanta & 0,596 & & 1.778 & .080 \\
\hline $\begin{array}{l}\text { Lingkungan Kerja Fisik } \\
\left(\mathrm{X}_{1}\right)\end{array}$ & 0,149 & 0,164 & 2.307 & .024 \\
\hline $\begin{array}{l}\text { Lingkungan Kerja non } \\
\text { Fisik }\left(X_{2}\right)\end{array}$ & 0,170 & 0,159 & 1.828 & .012 \\
\hline Kebosanan $\left(\mathrm{Y}_{1}\right)$ & 0,624 & 0,640 & 6.848 & .000 \\
\hline \multicolumn{5}{|l|}{$\mathrm{R}^{2} \quad: 0,725$} \\
\hline \multicolumn{5}{|l|}{ Adjusted $\mathrm{R}^{2} \quad: \quad 0,713$} \\
\hline \multicolumn{5}{|c|}{$\mathrm{F}_{\text {-statistik }}: 62,357$, Sig. $=0,000$} \\
\hline \multicolumn{5}{|l|}{$\mathrm{N} \quad: 40$} \\
\hline
\end{tabular}

Sumber : Hasil Olah Data Regresi Linier Model Jalur, 2018

Berdasarkan hasil regresi linier model metode OLS pada tabel 8 diatas Koefisien regresi positif (searah), berarti bahwa jika $\mathrm{x}_{1}$ dan $\mathrm{x}_{2}$ meningkat maka $\mathrm{Y}_{1}$ akan meningkat dan sebaliknya.

Tabel 9. Pembahasan Hipotesis

\begin{tabular}{|c|c|c|c|c|c|}
\hline Hipotesis & Variabel & $\begin{array}{c}\text { Koefisien } \\
\text { Pengaruh } \\
\text { Langsung }\end{array}$ & $\begin{array}{c}\text { Koefisien } \\
\text { Pengaruh } \\
\text { tidak } \\
\text { Langsung }\end{array}$ & $\begin{array}{c}\text { Koefisien } \\
\text { Pengaruh } \\
\text { Total }\end{array}$ & Keterangan \\
\hline $\mathrm{H}_{1}$ & $\mathrm{X}_{1} \longrightarrow \mathrm{Y}_{1}$ & 0,281 & - & - & $\begin{array}{l}\text { Berpengaruh } \\
\text { positif } \\
\text { signifikan }\end{array}$ \\
\hline
\end{tabular}




\begin{tabular}{|l|l|l|l|l|l|}
\hline $\mathrm{H}_{2}$ & $\mathrm{X}_{2} \longrightarrow \mathrm{Y}_{1}$ & 0,602 & - & - & $\begin{array}{l}\text { Berpengaruh } \\
\text { positif } \\
\text { signifikan }\end{array}$ \\
\hline
\end{tabular}

Sumber : Hasil Olah Data Regresi Linier Model Jalur, 2018

\section{SIMPULAN}

1. Lingkungan Kerja Fisik berpengaruh positif dan signifikan terhadap kebosanan kerja di Akademi Maritim Yogyakarta. Dengan arti bahwa jika Lingkungan kerja fisik meningkat maka kebosanan kerja akan meningkat.

2. Lingkungan Kerja Non Fisik berpengaruh Positif dan signifikan terhadap kebosanan kerja di Akademi Maritim Yogyakarta. Dengan arti bahwa jika lingkungan kerja non fisik meningkat maka kebosanan kerja akan meningkat.

\section{DAFTAR PUSTAKA}

Anies. 2005 Penyakit akibat kerja PT. Elex Media Komputindo Jakarta.

Basuki,. Susilowati. 2005. Dampak kepemimpinan dan Lingkungan Kerja terhadap Semangat Kerja. Jurnal IEEI Vol. 1 No.1.

Craparo, G., Faraci, Fasciano, P., Carruba, S.F., \& Gori, A. (2013). Journal Clinical Neuropsychiatry. 10, 3-4, 164-170.

Fahlman, Shelly A. (2009). Development and Validation of the Multidimentionall State Boredom Scale. ProQuest : Dissertations and Theses. (Online). (http://static1.squrespace.com/static/53a790784e4b01786c921de45/t/53a8 549ce4b0cd8d798e2d5f/1403540636545/Development+and+validation+of + thr+multimensional+state+boredom + scale $+\% 28$ diss. $\% 29+\% 28 \mathrm{Fahlman}$ \%2C+200 9\%29.pdf, diakses 20 Desember (2016).

Fahlman, S.A., Mercer-Lynn, K.B., Flora, D.B., dan Eastwood, J.D. (2011). Development and Validation of the Multidimentional State Boredom Scale.

Ghozali I. (2013). Aplikasi Analisis Multivariat dengan Program IBM SPSS 21. Edisi 7, Penerbit Universitas Diponegoro, Semarang.

Imelda Novelina Sihotang. 2004. Burnout pada karyawan ditinjau dari persepsi terhadap lingkungan kerja psikologis dan jenis kelamin. Jurnal PSYCHE. Vol. 1 No. 1, Juli 2004. Fakultas Psikologi Universitas Bina Darma Palembang.

Khotimah, K. 2010. Hubungan Antara Persepsi Terhadap Lingkungan Kerja Psikologis dengan Burnout pada perawat RSU Budi Rahayu Pekalongan. Skripsi. Semarang : Fakultas Psikologi, UNDIP.

Lalu Ciptadi Romadhoni, Thatok Asmony dan Mukmin Suryatni. 2015. Pengaruh Beban Kerja, Lingkungan Kerja, dan dukungan sosial terhadap Burnout pustakawan di kota Mataram. Khizanah Al-Hikmah : Jurnal Ilmu Perpustakaan, Informasi, dan Kearsipan Department of Library Science UIN Alauddin Makassar. Vol 3, No 2 (2015).

Leiter \& Maslach C. (1997). The truth about burnout: How organization cause personal stress and what to do about it. USA: Jossey Bass.

Mangkunegara, Anwar P. 2006. Evaluasi Kinerja Sumber Daya Manusia. 
Bandung: PT. Refika Aditama.

Nitisemito, Alex S. 1992. Manajemen Personalia. Jakarta: Ghalia Indonesia.

Notoatmodjo, S. 2003 Ilmu kesehatan masyarakat PT. Asdi Mahasatya Jakarta.

Ojekou, G.P. and Dorothy, O.T.. 2015. Effect of Work Environment on

level of work stress and burnout among nurses in a teaching hospital in

Nigeria.http://www.scirp.org/journal/PaperInformation.aspx?PaperID=608

15. Diakses tanggal 24 Januari 2017.

O'Mahony N. 2011. Nurse burnout and the working environment. Emergency nurse: the journal of the RCN Accident and Emergency Nursing Association 19(5):30-7 · September 2011.

Papu, J. 2002. Kebosanan kerja.http://www.epsikologi.com/masalah/110902.html

Potter, Beverly. 2005. Overcoming Burnout. Third edition. Oakland : Ronin

Rentzou, K. 2014.The impact of the work environment on Job Burnout.

http://mccormickcenter.nl.edu/wp-content/uploads/2014/12/2014-fall-

RN.pdf. Diakses tanggal 4 februari 2017.

Robbins dan Judge. 2003. Perilaku Organisasi, Jakarta : Salemba Empat.

Sedarmayanti. 2009. Sumber Daya Manusia dan Produktivitas Kerja. Bandung: CV Mandar Maju.

Suryani, T. 2013. Pengaruh Lingkungan Kerja terhadap kinerja pegawai. Governance, Prodi Ilmu Pemerintahan FISIP UNTAN. Volume 1. Nomor 01 .

Tilburg, Wijnand A.P.V (2011). Boredom and its Psychological Consequences : A Meaning Regulation Approach. Ireland. University of Limerick.

Yosep Budi Prasetya. 2009. Pengaruh Lingkungan Kerja fisik dan non fisik terhadap tingkat Stres dan Kejenuhan Karyawan. http://www.library.usd.ac.id/Data\%20PDF/F.\%20Ekonomi/Manajemen/05 2214084.pdf. Diakses tanggal 20 Januari 2017.

Yuwanto, Listoyo. (2012). Kebosanan dan FlowAkademik. Fakultas Psikologi Universitas Surabaya. (Jurnal Online), (http://www.ubaya.ac.id/2014/content/articles_detail/13/Stres-AkademikDan-Flow-Pada-Mahasiswa.html, diakses 20 Desember (2016).

Vodanovich, S.J. (2003). Psychometric Measures of Boredom: A Review of the Literature. TheJournal of Psychology. 137(6), 569-595. 